\title{
Research on the Development of Advertising Education in the Mode of "Internet Plus Education"
}

\author{
Lingling Zheng \\ School of Humanities, Xi'an University of Arts and Science, 710065
}

Keywords: Internet plus education; Advertising education; New development

\begin{abstract}
Internet Plus Education" is based on innovative elements of education as the core, is a new educational ecosystem in the digital age. The traditional advertising under the internet age is gradually replaced by the digital new advertisement. The current advertising education mode contradicts with the new demand of the industry. It is imminent to explore the advertising education of the internet plus innovation mode. This article explores the new development of advertising education from the perspective of interdisciplinary integration of Internet plus advertising teaching system, digital transformation, teaching methods innovation, innovation and entrepreneurship practice training.
\end{abstract}

\section{Statement of Problem}

In 2015, the Guiding Opinions on Actively Promoting Internet Plus Actions issued by the State Council pointed out that "Internet plus" is "integrating the innovation results of the Internet with various fields of economy and society to promote technological progress, efficiency improvement and organizational change, to enhance the innovation and productivity of the real economy and to create a broader new form of economic and social development featuring the Internet as a foundation for infrastructure and innovation. "Which shows that "Internet Plus" has become a new form. With the development of the times and the gradual formation of the Internet ecosystem, the cultivation of a new type of high-quality talents under the "Internet Plus Education" model has become a hot topic of concern to the educational circles. "Internet Plus Education" is not an online education, but an idea of change. It is based on the Internet as an infrastructure and innovative elements to innovate the organizational model of education, service mode, teaching mode, and so on, then build a new educational ecosystem in the digital age. Innovation and reconstruction of educational mode is not a simple multimedia teaching, but not distance education, online education, but the subversive reconstruction from the inside to outside.

The digitalization of the Internet has brought disruptive changes to the advertising industry. The operating model of traditional advertising industry has gradually been replaced by the new media digital marketing so that the quality structure of advertising professionals needs to be re-adjusted. This makes the positioning of higher education advertising and advertising professional development has changed significantly. Advertising education from the original mass media education gradually transformed into the Internet digital integrated marketing interactive education. This is a kind of innovative education that integrates Internet thinking. It is not a supplement to the original teaching but a deconstructed reorganization. Among the demands of society for application-oriented education, emphasis is placed on encouraging students to learn and feel in order to meet the needs of the industry, as well as the new dynamic of advertisement major students in internship and employment, all of which prompt us to discuss the status and future of advertising education. Therefore, it is imminent to change the teaching content and education mode of advertising education talents cultivation.

\section{The Contradiction between Advertising Education and Industry Demand under the Internet Age}

Contradictions with the Technical Requirements of Digital Media

Under the tide of digitization, the traditional advertising industry is gradually being replaced by the 
generalization of the new media environment in the Internet era with the programmatic of new media, forming the characteristics of the media era. New media application technology and cross-border cooperation needs more and more prominent, requiring advertisers to not only master the traditional advertising technology, but also to integrate new media, new advertising technology, cross-border disciplines and other applications under the background of digital technology. Therefore, competing advertisers in the digital age need to extend basic ideas to all areas, not just basic advertising performance skills, but also full mastery of big data from other industries in other sectors to make that happen integration. At present,the college education in advertising with a channel of new media is still in the stage of exploration, far from meeting the changing needs of the industry. The education of students is also rarely involved in new and emerging media technology courses, most of which are traditional basic courses and theoretical majors. Once the students enter the society, they find that there is a big gap between what they learn in the classroom and the reality, and they can not adapt to the impact of the new environment at all. The technical talents trained in closed traditional education do not have the ability to adapt to change. Thus, the school education and social needs are disjointed. Therefore, on the one hand, the teaching environment needs to be open, and colleges need to increase the relevant digital technical operation and Internet thinking courses; On the other hand, it is crucial to enhance the capacity of multidisciplinary integration in the digital environment of students so that digital advertisements in the developing world can be adapted and qualified more quickly only by developing multi-disciplinary talents with multidisciplinary knowledge and skills.

\section{Contradiction with the Demand of Digital Integrated Marketing}

"In 2016, the scale of Internet marketing in China reached 290.3 billion, an increase of $32.9 \%$ over the same period of previous year. The growth rate far exceeded that of other media. In 2016, Internet marketing accounted for $68 \%$ of the total advertising market, which was the main driving force for the marketing industry." Which can be seen that the Internet marketing communications has become a major part of the advertising market. Internet marketing communication is the integrated marketing of digital marketing with the integrated symbols of images, sounds and videos as the content carrier. It transforms the single media of mass media into the three-dimensional comprehensive and full-dimension communication, and its interactive participation is significant feature in the age of digital marketing era. Advertising in the era of digital integrated marketing has the characteristics of rapid propagation, massive information and intercultural regions. The depth and breadth of digital advertising have surpassed traditional advertising in the age of mass media. The mode of advertising operation goes to large areas of advertising, and it pays more attention to digital integrated marketing communications. It can be said that the idea of digital integrated marketing is the core of advertising development in the future. It is the development trend to propose accurate marketing plan for user activities under big data. This requires that advertisers have a high degree of digital integration and management analysis. The current teaching model of advertising education is still using the public creative ideas and the notion of mass media to teach. As far as the current system of traditional advertising education is concerned, it places a great deal of emphasis on a certain mode of communication. However, the teaching on the combination of different modes of communication and the evaluation of the results in actual operation is still in a state of decomposition. Therefore, the majority of schools can not establish a complete system of student knowledge theory and practice structure, advertising courses are relatively old closed. Even many teachers have limited knowledge of digital marketing, has been unable to meet the changing needs of the times.

\section{Contradiction With the Demand of Talent's Practical Ability}

In the era of the Internet, advertising is the precise positioning and dissemination of big data technology, which is more digital and three-dimensional. The traditional advertising marketing and empirical evaluation have been unable to meet the needs of the development of the current era, practitioners need to have rich practical experience in digital communication. In terms of advertising education and teaching, the content of the curriculum system still follow the traditional model, advertising practice teaching is also a weak environment. The existing teaching mainly 
focuses on practical training. From the aspects of teachers, teaching contents and training forms, it obviously lags behind the needs of the industry. In addition, there are many factors that restrict the practice of various kinds of education. Some teachers have no experience only can copy textbooks and lack of practical foundation without flexibility, which reduce students' interest in learning. The ability of the students can not be exercised, and the contradiction with the demand of the industry is becoming more and more obvious.

\section{New Development of "Internet Plus Advertising" Education Model}

"Internet Plus is a new development background, a new mode of thinking, a new educational content, a new way of learning and a new mode of management for higher education." Changes in the new way of thinking lead to a series of changes in the relationship between the internal needs of education and restructuring system.

\section{To Reconstruct Curriculum System by Cross-Border Integration Thinking}

The "Plus" in "Internet Plus" expresses a kind of cross-border, which is the result of its connection with others. It creates a new form on the basis of cross-border connection. It uses Internet thinking to educate whole and part of innovation. Education has undergone a qualitative change, reaching a high level of leap. The comprehensiveness of advertisement discipline determines that advertisement education is a multi-discipline background that includes economy, news media, society and culture and arts, and interdisciplinary is an important feature of advertisement education. Therefore, advertisement education should open up academic barriers, adapt the curriculum system to adapt to the changing needs of the industry with the thought of cross-border integration of Internet thinking, and should break the boundaries of disciplines in teaching and integrate teaching resources in different fields so as to guide students to actively seek inspiration and boldly create. The digitized dissemination of Internet media has made the boundary between disciplines and disciplines more and more vague. In the process of dissemination, all kinds of subject boundaries have begun to converge, which are big data information of digital living space. The value of advertising is to bring practical effects to advertisers. From this perspective to think advertising education, in fact, all disciplines are not isolated, but a linked whole. It can provide nutrition for advertising education, enrich the thickness of subjects and expand the breadth of disciplines.

\section{To Expand the Teaching Content by Digital Transformation}

In the Internet era, digital marketing communication has profoundly changed the competition pattern in the advertising industry. The digital information technology and data manipulation capabilities have become important capabilities in the advertising industry. However, the educational philosophy of advertising profession has not been completely changed. Which requires adjustment to enrich the curriculum content. First of all, we will increase the content of specialized teaching in areas related to digital marketing analysis, master digital technologies through market data mining, statistics and analysis, and use professional software to operate and understand the value of data and analyze market changes. Second, to increase the number of technical works of practical projects, and through the production of advertising to master digital multimedia tools. Such as H5 and short video ads, playing on high-traffic websites or micro-blog and WeChat with rich multimedia presentations and high interactivity for high clicks and interactions. Finally, with the help of production and teaching integration platform, we will increase actual data marketing training in teaching, and combine different digital media for advertising. In this process, we will enhance our actual digital technologies and analysis skills.

\section{To Update Teaching Methods by 020 Teaching Way}

$\mathrm{O} 2 \mathrm{O}$ teaching mode is a new type of teaching mode of interaction between teachers and students. Internet $\mathrm{O} 2 \mathrm{O}$ online learning mode has opened up a new teaching situation. Online courses based on MOOC and micro-class small videos not only expand the learning style but also fully demonstrate the autonomy, enthusiasm and interactivity. On the Internet with the theme of issue to learn autonomously, offline to summarize and communicate. The advertisement teaching can use the professional APP or online class to launch the subject problem presupposition, the group 
discussion, the designated plan and the discussion summary. In this process, students can choose their own learning methods and group roles, and gradually become the organizer of learning activities. Teachers play a leading role in the activities. Second, we can make use of online teaching to set up an ad information database and admissions guide micro-class, to form a combination of resource library and personality course, to analyze students' individual needs based on online data, and to further customize and further study. The third is to establish cooperative relations with advertising enterprises in the $\mathrm{O} 2 \mathrm{O}$ mode, optimize the combination of educational resources with the latest resource information of the social industry through online sharing, and extend the learning of students to valuable fields outside the classroom and school. Fourthly, the implementation and dissemination of the activity cases in advertising teaching can be carried out in combination with WeChat, micro-blog, video websites and other media. This $\mathrm{O} 2 \mathrm{O}$ mode can be used to conduct practical exercises on small-scale projects and judge and test them through clicking, liking and the number of playing.

\section{To Enhance Practice and Explore by Innovation and Entrepreneurship}

The model of "Internet + Education" breaks down the existing various relational structures, fundamentally changes the relationship between teachers and students, and between educational institutions and learners. It truly integrates public wisdom and is more conducive to innovation and entrepreneurship. "The new media ads themselves and the traditional post-processing of ads require new media skills, and the operational skills of new media ads are both artistic and technical, therefore require a large proportion of experimental teaching to be supported. " Exploring the advertising practice teaching is the development needs of the times, give full play to the advantages of open innovation network, combined with network technology resources, the introduction of advanced industry advertising education resources, constructing the perfect practice platform, build all kinds of public record of teaching space, the campus entrepreneurship training normalization, to provide students with a platform for innovation and entrepreneurship practice more. Strengthen the project of cooperation between schools and enterprises, build a perfect campus practice platform, and form a stage systematic innovation training based on the real project of enterprise projects so as to enhance the level of practice teaching. In summary, the "Internet Plus" model not only changed people's lives and ways of thinking, but also opened up new dimensions of thinking for education in advertising, integrating and innovating across borders, transforming digital marketing, optimizing online learning, and innovating practices. Attention should be paid to the coordination between professional education and individual development of students. The transformation of advertising education is to upgrade itself with the help of the Internet revolution and cultivate a new generation of talents for the advertising industry in the Internet age.

\section{References}

[1] Yao Xi, Li Chunling.Deconstruction and Reconstruction of China's Institutional Advertising Education System from the Perspective of Internet, Big Data and Marketing Communication Structuralism .News and Communication Review [J] .2015 (00): 163-178

[2] Chen Gang. Thoughts on digital transformation of advertising education. Journalism and writing $[\mathrm{J}] .2017$ (10): 31-35

[3] Liao Bingyi.Advertising Education Reform in the Digital Era.News Chun Qiu [J] .2016 (01): 73-77

[4] Liu Xinghe. Construction of a New Model of Advertising Education in All Media Era [J] .2015 (02): 138-142

[5] Chen Peiai. Reflections on Chinese Advertising Education Reform in the Digital Era. Advertising Research [J] .2011 (04): 31-36

[6] Shu Yongping: advertising education innovation under the trend of new media advertising, advertising research $[\mathrm{J}] 2008(02): 84$

[7] Liu Wei. $\mathrm{O} 2 \mathrm{O}+$ actual combat teaching: Internet + educational background advertising professional development path. Advertising Daguan [J] .2016 (04): 59-63

[8] Chen Li, Lin Shi-yuan, Zheng Qin-hua. Opportunities and Challenges of Distance Education in 
China in the "Internet +" Era [J] .New Distance Education Research, 2016, (1): 3-10.

[9] Xie You-ru, WU Li-hong, Qiu Yi, Zhang Hui-yan, Li Wei. Innovative Teaching Practice Research Based on Internet Thinking: Curriculum Perspective. China Electrochemical Education [J] .2017 (10)

[10] http://www.chyxx.com/industry/201710/576017.html Forecast of China's Advertising Industry Market Prospect and Development Trend in 2017 